\title{
Mi conciencia de mí: ciudad y memoria en Santiago Waria de Elvira Hernández*
}

\section{Mi conciencia de mí: city and memory in Santiago Waria by Elvira Hernández}

\author{
Karem Pinto \\ Facultad de Filosofía y Humanidades, Universidad de Chile, Chile \\ karempinto@yahoo.com
}

Resumen • El presente trabajo expone un análisis del texto poético Santiago Waria (1996) de Elvira Hernández, en base a dos puntos de reflexión: la ciudad de Santiago como territorio que escenifica el proceso postdictatorial chileno y el trayecto de (auto)configuración de la identidad de su hablante poética, constituida en el reconocimiento de la alteridad sexo-genérica reunida con la diferencia política y étnica. El análisis expone la relación de ambas líneas, pues con una actitud disidente al proyecto político de la Concertación, la hablante poética provoca la apertura de los contenidos traumáticos constitutivos de la historia nacional, dejando al descubierto los mecanismos de su ocultamiento; mientras declara la diferencia de su experiencia, en un gesto que, por un lado, instala el rol de la mujer en la escena escritural y, por otro, reivindica el rol social crítico de la/el poeta.

Palabras clave: poesía chilena, mujeres, postdictadura, memoria, ciudad.

Abstract - This paper presents an analysis of the poetic text Santiago Waria (1996) by Elvira Hernández based on two reflections: the city of Santiago as a territory that stages the post-dictatorship Chilean process and the identity's trajectory of the (auto)configuration of her poetic voice, which acts as a recognition of an otherness as gender in its political and ethnic difference. The analysis describes the relationship of both lines with a maverick attitude to the Concertación's political project; the poetic speaker provokes the opening of the National History's trauma, revealing the mechanisms of concealment while declaring the difference in her experience in a gesture that install the role of women in the writing scene as well as the revindication of the poet in their critical claims and social roles.

Key words: Chilean Poetry, women, post-dictatorship, memory, city.

* El presente artículo se enmarca en los proyectos de investigación Fondecyt N ${ }^{\circ}$ 1110038, "Memoria y escritura poética de mujeres en el Cono Sur de América, 1972-2010» y DI SOC-VID, N 10-02-02, «Poéticas en torno a las memorias individuales y colectivas en escrituras de mujeres del Cono Sur (19732010)", de la Universidad de Chile. Ambos proyectos a cargo de la Dra. Alicia Salomone, de la Facultad de Filosofía y Humanidades de la Universidad de Chile. La autora es actualmente becaria CONICYT. 
Algo se fugó de nosotros mismos su ausencia fundó la ciudad

Elvira Hernández

¿Acaso no nos roza, a nosotros también, una ráfaga del aire que envolvía a los de antes? ¿Acaso en las voces a las que prestamos oídos no resuena el eco de otras voces que dejaron de sonar?

Walter Benjamin

Escribiendo una obra alimentada por mi historia me crearía yo misma de nuevo y justificaría mi existencia. Al mismo tiempo serviría a la humanidad.

Simone de Beauvoir

La primera vez que leí Santiago Waria (1996) no pude explicarme la enorme sensación de desconcierto que me provocó. No es fácil revivir, de la mano de su hablante, el trayecto por ese Santiago gris de la posdictadura; una conmoción aumentada al comprender que la explosión temporal que el poema propone abarca no sólo ese oscuro período, sino también otros, igualmente viles y silenciados, que también forman parte de nuestra historia nacional. Pero, más allá, resulta profundamente desolador advertir que el alcance de su lectura nos habla de un relato actual, de un presente abandonado y enceguecido, hoy, en nuestros propios días. Santiago Waria $(S W)$ se convierte así en un registro histórico de la violencia sobre la que se ha levantado la conformación de nuestra nación y que aún pesa. El pasado que no pasa y del cual debemos hacernos cargo, un acto que Paul Ricoeur llamara el «deber de memoria» y que Walter Benjamin demandara asumir parecen calzar de manera perfecta con el proyecto poético del texto que aquí se analiza.

La producción de $S W$ se realizó, tal como se especifica en su última página, "en Santiago de Chile/ entre los entontecidos/ años de 1989 y 1991» ${ }^{1}$. De tal manera, la desfachatez con que la autora califica a ese período (o a las personas que lo vivieron) encuentra directa explicación allí, en los acontecimientos que siguieron al término de la dictadura militar, pero también en los precedentes, los que resultan vitales para comprender el sentido de la obra.

A más de dos décadas del inicio de la transición (1990), podemos recordar cómo se transformó en una broma reiterada la mención al júbilo que la canción de la campaña concertacionista prometía ("Chile, la alegría ya viene»). Sin embargo, más que una sana expresión de humor, resultaba ser una extendida queja llena de amargura, al igual que la apreciación de Hernández, porque luego del triunfo del NO (1988), en las elecciones que decidieron el término del gobierno militar, fueron quedando expuestas, una a una, las inconsistentes bases del restablecimiento democrático.

En ese marco, el poema irá construyendo en su curso una imagen crítica de la ciudad y su comunidad, vinculada a la pérdida de la memoria y la instalación del proyecto neoliberal de la «nueva democracia» como ideología dominante. Mientras que, en oposición a ello, la voz central realizará un trayecto que culminará en el reconocimiento de una

\footnotetext{
El formato de este texto poético no contempla la numeración de páginas (con excepción del poema central), ella es reemplazada por las letras del abecedario, ya sea integradas o no al título del poema o su primer verso. En este caso la última página es evidentemente $Z$ de «Zaga y final». Así es indicada en su propio índice y así será anotada en los versos aquí citados.
} 
204

identidad singular conformada por una red de diferencias que, desde la posición sexogenérica, se encuentra con la alteridad política y étnica, y que instalará poderosamente la presencia de la mujer en la escena escritural, reivindicando a la vez el rol social de la/ el poeta en la sociedad contemporánea.

Así, podemos postular que $S W$ corresponde a una obra representativa de esa experiencia social en formación (Williams) que, en resistencia al establecimiento del programa de nación posdictatorial, expresa una posición de quiebre comunitario y la afirmación de una identidad personal ingobernable de la voz principal, bajo tal estatuto clausurante del pasado inmediato. Ese sentimiento, que comienza a visibilizarse en el texto poético de $S W$, tendrá uno de sus primeros análisis teórico-críticos terminando la década de los 90, en el que fuera el más famoso de los estudios elaborados por Tomás Moulian, récord de ventas durante los años posteriores, me refiero a Chile Actual. Anatomía de un mito. Allí, en uno de sus apartados, el sociólogo explica extensamente las deslucidas circunstancias políticas y sociales que envolvieron al país a partir del plebiscito de 1988, relativas a una serie de señales legitimadoras del régimen militar ${ }^{2}$, un panorama que volvió a ser revisado y corroborado por diversos intelectuales tras la detención de Pinochet en Londres, en 1998 (Richards, Políticas).

Desde su apertura, el discurso poético va desplegando una serie de señas demandantes de unidad (títulos, subtítulos, fechas, epígrafes, nombres, películas y lugares), las que van profundizando en su voluntad de rememoración crítica, entendida como un ejercicio de esfuerzo intelectual o búsqueda activa - la zétésis socrática o anamnésis aristotélica (Ricoeur)—, ejecutada desde una posición que instala en el centro de su discurso el lugar de la diferencia, la mirada del otro. Entre esos vectores de lectura, los tres títulos iniciales, dos de los cuales pueden ser entendidos como subtítulos, señalan que $S W$ remite particularmente a la ciudad de Santiago, y, sobre ella, el primer subtítulo agregará las fechas de su fundación (1541) y el período de la escritura de la obra (1991), como ya se ha señalado que dice el paratexto final $(Z)^{3}$. En esa misma página, abajo, aparece el primer epígrafe que indicará la perspectiva de enunciación de su hablante. En él se lee:

Así como Atenas fue astu para los griegos y Roma urbs para los romanos Santiago fue waria para los mapuches como cualquier otro poblado

La mención de las grandes civilizaciones de la historia occidental y sus principales centros urbanos (griega y romana; Atenas y Roma) marca la atención del enunciado que, en segundo o tercer plano, agrega a la ciudad de Santiago, primera ciudad fundada por los españoles en Chile. Lo importante allí, más que esa supuesta y desmedida compara-

2 Entre esas medidas Moulian destaca la aprobación de la Constitución de 1980 (febrero de 1990), la ceremonia oficial del cambio de mando (marzo de 1990) y, más tarde, la creación de la Comisión Verdad y Reconciliación (abril de 1990), que culminó con el Informe Rettig (febrero de 1991), estableciendo la responsabilidad criminal en la comunidad entera (imposible olvidar ese «Todos somos culpables», en la temblorosa voz de Patricio Aylwin, vía cadena nacional), una condena que, en realidad, el Ejército nunca asumió. De allí que Moulian, desde su propia situación temporal, precise la superficialidad y dependencia de la nueva democracia, dedicada a la reproducción de un orden social basado en la propiedad y la ganancia privada, la limitación de la acción colectiva de los asalariados y la tutela militar en el plano político (49).

3 Que fue aclarado anteriormente. Recordemos, además, que el texto carece de numeración, por lo tanto, cada cita irá seguida por la letra correspondiente, al final y entre paréntesis. 
ción («Así como»), es el quiebre que produce la intervención de la presencia mapuche, indicando con ello el primer acto de colonización y expropiación de las tierras indias. Esa lectura es acentuada por la preferencia de la mirada étnica sobre la ciudad levantada por europeos, ya que - en mapuchedungun - es nombrada waria, añadiendo, en tono que tiende a la paridad, "como cualquier otro poblado». En consecuencia, Santiago, expuesta en su presunción de origen primermundista, no sólo es señalada en su bárbara conformación, sino que además pierde su calidad de centro, capital o núcleo urbano. Desde esa posición, cercana a la perspectiva indígena, desvinculada o descentrada, mejor aún, insubordinada, la hablante lírica enunciará su discurso.

La reunión de fechas (1541-1991), entonces, adquiere una clara lectura, pues con ellas la voz central declara que la usurpación, los excesos y la injusticia han subsistido a lo largo de nuestra historia y se prolongan desde su fundación hasta su propio acontecer posdictatorial. Y así, con un enfoque crítico expansivo, avanzará hacia esa especie de ciudad-espectáculo que intenta atraparla como sujeto pasivo, sin esperar su respuesta cargada de hostilidad e ironía, como testimonio de su visión sobre los acontecimientos y actitudes que irá reprobando en el transcurso de su recorrido. Tal como Benjamin lo quería, ella no permitirá que el pasado sea adormecido y borrado, sometido al dominio del presente, por el contrario, a medida que se traslada por la ciudad posdictatorial, irá despertando a los muertos y reuniendo lo destrozado (54).

La acción poética comienza con un juego de espejo en el que la autora realiza un procedimiento de diferenciación e identificación entre su calidad de poeta y sujeto civil. En esos versos, la voz central indica su presencia como sujeto de la enunciación (yo) haciendo uso de una actitud apelativa o apostrófica dirigida a un objeto lírico, personificado en el nombre real de la escritora, pero intervenido («Anda Sola Teresa»/ María Teresa Adriasola, «Tú» $\left.{ }^{4}\right)$; levantando, de ese modo, un discurso poético referencial, anclado a los contextos sociales, políticos, históricos y culturales, y marcando, con ello, la posición crítica de la/el poeta en la sociedad ${ }^{5}$. Asimismo y en consecuencia, al corroborar a lo largo del texto que esa voz enunciante corresponde a una voz de mujer, queda inscrita en la obra el lugar génerico-sexual de su producción y su posición al interior del sistema sexo-género ${ }^{6}$, concepto con el que Gayle Rubin designó a «esa parte de la vida social que es la sede de la opresión de las mujeres» y que definió como el «conjunto de disposiciones por el que una sociedad transforma la sexualidad biológica en productos de la actividad humana, y en el cual se satisfacen esas necesidades humanas transformadas» (97). La denuncia de su oposición a las desigualdades de ese sistema es enfatizada a través de la doble negación del signo patriarcal producida en este nombre propio, al decir del verso: la omisión de su

En referencia al nombre, ver el sitio web Memoria chilena.

Otra lectura podría entender el yo enunciante de este poema como una voz omnipresente, que con tono malicioso invita al personaje poético a formar parte de la escena puesta en cuestión, pero la interpretación propuesta se basa en el tono irónico y crítico expuesto aquí y a lo largo del poema. Como veremos posteriormente, este yo queda resuelto en el poema «Yo, Elvira Hernández». En su vínculo se agrega la cita de Pessoa ( Mi conciencia de la ciudad, es/ por dentro, mi conciencia de mí») como directriz de lectura en primera persona que tiende al relato de la experiencia propia.

6 Raquel Olea ya ha hecho referencia a la imbricación de la hablante poética y la autora, mencionada en el mismo texto («Anda Sola Teresa vieja», A/ «Yo, Elvira Hernández», Y). Sin embargo, no me parece clara la referencia al proceso de empoderamiento que Hernández hace de su rol de poeta a través de ese gesto. Dice Olea: «Es Santiago Waria uno de los textos de Elvira Hernández donde esta autoría se explicita como construcción de sí misma", y más adelante, "Peregrina de su ciudad desértica se busca en ella y busca infructuosa el sentido de estar allí» (s/p). 
primer nombre (María, referido a la Virgen como modelo de domesticación femenina) y la velación de su apellido (Adriasola, como marca del sistema androcéntrico en la/el sujeto).

De esa manera, despojada de las marcas del padre, la voz poética inicia su trayecto a través de un camino cercado por "misterios», "cizallas» y "perros de vidrio molido", aproximándose a la ciudad, «a sólo seis kilómetros», donde «Sodomas y Gorgonas» la esperan. Así la urbe, que como podemos recordar simulaba semejanza con Roma y Atenas en el epígrafe inicial, será reproducida en una cantidad de figuras humanas degradadas, monstruosas, fantasmales y en estado de permanente miseria. Un tránsito que me recuerda el descenso de Dante al infierno en la Divina Comedia, pero que en este caso, tratado con menor solemnidad, tiene aspecto de circo pobre.

Dicha referencia al viaje de características infernales no es gratuita («cielos corruptos, sólo queda desembarcar», señalará pronto la hablante, B), cercana en su simbólica de muertos clamantes y sin descanso, puede ser interpretada desde los conceptos de duelo y melancolía definidos por Freud, a partir de los cuales varios autores (Jelin, Los trabajos, Avelar, Ricoeur, entre otros) han identificado la dinámica de padecimiento o sanación del trauma provocado por la violencia política. Para ellos, tal como advierte Ricoeur, es posible extender el análisis freudiano del duelo al traumatismo de la identidad colectiva, "no sólo en un sentido analógico sino también en los términos de un análisis directo, de traumatismos colectivos, de heridas de memorias colectivas» (108). De esa manera, se plantea la oposición entre ambos conceptos, entendiendo al duelo (introyección) como la separación del yo del objeto perdido, la superación de la ausencia y liberación del trauma, mediante un trabajo o proceso que indica una elaboración crítica sobre lo vivido y la capacidad de interpretarlo; y, por otro lado, se alude a la melancolía (incorporación), que Jelin relaciona con el exceso de memoria (Los trabajos, 14) y Ricoeur con memoria herida, enferma o compulsiva (81-124), como la identificación absoluta del sujeto con el objeto perdido, alojándolo dentro del yo como un cuerpo forastero, que se manifiesta en forma críptica y distorsionada, levantando una tumba intrapsíquica en que se niega la pérdida y donde el objeto perdido es enterrado vivo. En consecuencia, bajo esas nociones, la representación de la ciudad que construye la hablante lírica de $S W$ puede ser comprendida como una realidad de cripta social, resultante del proceso de transición obstructivo del trabajo de duelo.

En tal sentido, podemos acercar la perspectiva del sociólogo chileno Tomás Moulian, al referirse puntualmente a la legitimación del régimen militar promovida por los gobiernos de la Concertación, especialmente respecto de la apropiación y fervorosa aplicación del modelo económico neocapitalista, lo que, según su opinión, significó el desvío de los ánimos de verdad y justicia sobre los abusos políticos del Estado dictatorial, impidiendo el debido proceso a una parte de nuestra historia que necesitaba ser resuelta pública y judicialmente. A ello se refiere Ricoeur cuando precisa que el «deber ético-político» de la memoria se establece como un tercer término en el punto de unión del trabajo de duelo y del trabajo de memoria, el que requiere materializarse en un imperativo de justicia que establezca cargos y reparaciones de valor ejemplar (118).

En esa dirección, el poema realizará el descubrimiento de una serie de mecanismos impulsados por el gobierno de la Concertación tendientes a la exaltación del presente como espacio de armonía social y progreso económico, con el objetivo de aplacar el 
pasado, las llamadas «políticas del olvido» (Jelin, Los trabajos, 29; Ricoeur, 110) ${ }^{7}$. Entre ellas, ese pretencioso discurso de país exitoso, inserto en el desarrollo del mercado mundial, demostrando una sólida marcha en la obtención de la democracia, es recreado poéticamente a través de diversos pasajes. El poema «M................" presenta una clara muestra elaborada mediante la exhibición de una ostentosa imagen de tarjeta postal, sin embargo, su suspicacia es declarada desde el mismo título. Su texto dice:

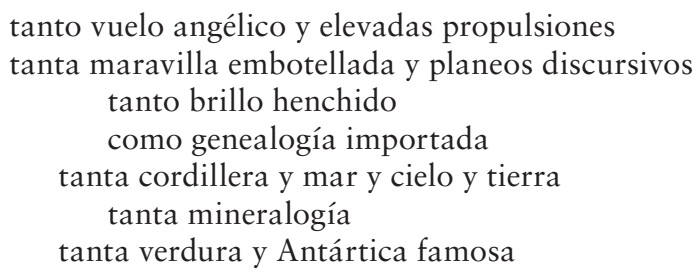

En ese entramado, la hablante señala la presencia de Chile en la célebre Expo Sevilla de 1990 («Antártica famosa»), donde la representación nacional quedó a cargo de un inolvidable iceberg, símbolo de frialdad, transparencia y pureza, con el que Moulian identificó el ansia de «blanqueamiento" de nuestro país a nivel público e internacional (34). El poema desmonta esa ambición de comarca feraz, exportadora de riquezas naturales, de un Estado modelo sustentando la «Transición Perfecta» (33) y, en ese sentido, se deja oír la rotunda condena de sus versos finales: «tanto tanto tanto/ y nada».

Ese tono acusativo estallará a lo largo del poema a través de múltiples imágenes que ponen en tela de juicio el aparente estado de prosperidad nacional y que buscan descubrir su situación real de país entregado, en consecuencia, como escenario de enajenación ciudadana y en permanente estado de agonía social, testigo silencioso del accionar oculto y despreciable de sus autoridades. Señala la hablante:

Se perdieron 20 años de nuestras vidas. Fue una lotería arreglada. Nunca supimos cómo se conquistaban las ganancias ni que la vida fuese tan loca. El tropelista jugó bolos con nuestros huesos. Nos ganó el quién vive en una mesa de trucidamientos y vivisecciones. Nos condenó a caminar por la calle de la morgue que es Avenida La Paz. Los jueces dormían el sueño que sigue al almuerzo. Somos ambulantes callejeros, con veinte años muertos a nuestras espaldas como una joroba o una pierna lisiada, imposibilitados de escalar el futuro (J).

La voz poética hace y hará uso frecuente de la ironía para expresar, claramente, con sentido de quiebre, su perspectiva contraria al acontecer político y social («Nunca supimos [...] que la vida fuese tan loca»). Sin embargo, esa figura retórica es modificada, al igual que en el poema anterior $(\mathrm{M})$, con la interposición de un amplio espacio (o silencio) entre esos versos y el de cierre, enunciado con un tono de gravedad afirmativa que da fuerza a la modulación de su sentencia:

«Recalco,

se perdieron veinte años de nuestras vidas».

Señala Jelin: «Las borraduras y olvidos pueden también ser producto de una voluntad o política de olvido y silencio por parte de actores que elaboran estrategias para ocultar y destruir pruebas y rastros, impidiendo así recuperaciones de memorias en el futuro» (Los trabajos, 29). Paul Ricoeur también hace referencia a ese mecanismo cuando se refiere a la memoria instrumentalizada o manipulada como un ejercicio ideológico (110-118). 
En la línea citada, el poema «Ñoña por doquier» mantiene el afán de caracterización de la ciudad como expresión de letargo y derrota. En esta ocasión, el texto se manifiesta como un retrato total del ambiente de pasividad que consumió a la ciudadanía (en el desayuno, las micros, los vidrios, edificios y balcones, en los jardines infantiles), contemplante de la inmoralidad de las autoridades y la acomodación de políticos, intelectuales («entre políticos apolíticos y cientistas de pelaje plástico») y artistas («la sacaron con pinzas desde los poros de la vanguardia teórica del arte y la literatura»). Sobre ellos, «vivarachos todos/ espías de la vida en general» (E), entregados a los «oleajes de posmodernidad» $(\mathrm{O})$, resuena su permanente reproche: «vivificantes hasta lo último/ vivir no es avivarse» (E). Bajo el análisis de Moulian, ese ánimo resignado y complaciente detallado en $S W$ se materializó en una posición de política consensual que, como símbolo de una supuesta armonía y pretendido diálogo igualado, devino en una forma superior del olvido, al anular las divergencias y desacuerdos naturales en una sociedad real, además, en etapa de intenso cambio. Por tanto, lo que su sistemática indicación pretendía era más bien la homogeneización de la sociedad y la evaporación del sector disidente, imponiendo un entorno de silencio y la estigmatización sobre los intentos de movilización contestataria. Atentar contra el consenso fue planteado como una conspiración en contra de la frágil democracia y la paz cotidiana (39). En ese escenario, agrega Moulian, hasta los enfoques enunciados en los años 80 , adversos a la instalación del neoliberalismo, fueron fagocitados en los 90, revelando un claro viraje político ${ }^{8}$. Desde la misma Concertación había una absoluta negación de los "deseos esenciales del pasado para reconocer que en la sociedad de Pinochet existieron núcleos racionales básicos» (38), como la economía y la estructura social. Y en esa dirección los gobiernos concertacionistas encaminaron múltiples esfuerzos hacia la conquista de los empresarios, los militares y la derecha, con el objetivo de «que los agentes económicos mantuvieran su confianza» en la estabilidad del proceso (40).

La «instrumentalización de la memoria y el olvido» (Jelin, Los trabajos, 14; Ricoeur, 111), aunque respondía a una experiencia traumática difícil de abordar, provenía claramente de un sistema de trueques en que la Concertación cambiaba silencio por estabilidad, dando por justificación para cualquier situación conflictiva las famosas «razones de Estado» $(36)^{9}$. Esa estrategia, manifiesta la hablante de $S W$, es respaldada por el mutismo de una «Sociedad Robótica y Mendicante» (L), que deseosa de normalización social fue persuadida por la facilidad de adquisición de bienes en el nuevo sistema mercantil. Disconforme, la voz poética, rehúsa la actitud doblegada e indiferente de esa masa ambulante «por las anchas alamedas/ de la vida alegre» (P), y, en cambio, opta por el registro del

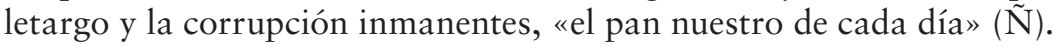

Un poema significativo, en ese sentido, es «Fuente Neptuno», ya que en él se activan una serie de referentes esenciales del texto. Primero, tal como en su inicio, se abre una perspectiva histórica de amplio alcance, evocando una vez más la fundación de Santiago mediante la imagen del cerro Santa Lucía, entonces Welén, como sitio testimonial de la

El autor se refiere directamente a Alejandro Foxley, Eugenio Tironi y José Joaquín Brunner (42-44).

Esa realidad semidemocrática, condicionada a la tutela del ejército, quedaría en total evidencia en el desfile militar de septiembre de 1990, cuando el general Parera no solicita autorización al presidente Aylwin para iniciar la exhibición. A esa situación podemos agregar la movilización del ejército motivada por la investigación de los millonarios cheques que, a nombre del régimen militar, había cobrado uno de los hijos de Pinochet, Augusto Pinochet Hiriart, el denominado «Ejercicio de enlace», ejecutado en diciembre de 1990 y que puso fin en el gobierno de Frei a un posible proceso (Memoria Viva). 
violenta usurpación de tierras indígenas. Un lugar escogido intencionadamente, en un segundo gesto, ya que entre 1872 y 1875 fue objeto de una costosa remodelación emprendida por el entonces intendente Benjamín Vicuña Mackenna. Por tanto, esa elección sugiere el emplazamiento de un espacio histórico representativo de la instalación del Estado moderno y, sobre él, se apunta al embellecimiento, o mejor dicho, al enmascaramiento de un lugar signado por la brutalidad. Así, por un lado, el poema en cuestión pretende ser la representación microscópica de la comunidad ciudadana, y, por otro, se convierte en cronotopo privilegiado que reúne pasado y presente (como las fechas iniciales del texto) en una continuidad de operaciones históricas y también criminales. Señala la hablante poética: «Esto es peor que cruzar la Avenida Cardenal Caro. O que Escila y Caribdis en seco. No se respira el salobre mar sino amoníaco puro. Amén del monóxido y el hollín por mil. Es el Novus Orbis vomitado: Ngechén en la Cruz y en la picana (F).

En la relación entre título y contenido, el poema reconstruye un imaginario mítico marino a través de diferentes actantes («Neptuno» y su «tridente», un «pulpo», «Escila», monstruo de doce pies y seis cabezas y «Caribdis», quien causaba enormes remolinos ${ }^{10}$ ), a los que luego agrega «cupidos», «príncipes», «reinas», «reyes» y «vampiros», de manera tal que el centro urbano es expuesto como un lugar delirante, lleno de peligros y eminentes muertes, tóxico y nauseabundo, en el que cualquier intento de salvación es infructuoso, como la misma hablante lo comprueba, y donde la negación no acusa recibo («yo he lanzado mis cupidos a más no poder» ${ }^{11}$ ). Éste, pareciera decir, es hoy el sitio que ayer presenció la condena a desaparición del pueblo mapuche, identifica en la muerte de su máxima divinidad Ngechén, víctima, por partida doble en un salto a través de la historia nacional, que va desde la imposición religiosa en períodos de conquista española («Cruz») hasta las torturas aplicadas por el régimen militar («picana»). Continúa la descripción ciudadana de la siguiente forma: «Los príncipes del peñasco se quedarán en las laderas salivando un pito. Las reinas de la noche pasarán derecho al fornicatorio. Los caminos yacen atestados y el cerro se mueve como un pulpo. Los reyes del sablazo establecen pronto sus capitales. Los vampiros tienen puestos sus guantes de gasa» (F).

Finalmente, la imagen de ese «sablazo», significante del autoritario corte en la historia de nuestro país mediante la implantación del nuevo régimen económico impuesto no con «guantes de seda» como reza el dicho, aunque también deja leerse, sino con «guantes de gasa», es decir, mediante una operación en la cual los ejecutores sustentan en sus propias manos las huellas de la muerte, tapando las heridas, ocultando crímenes, imponiendo sobre ellos el silencio, «la borradura del pasado como pasado» (Oyarzún, 32).

Son abusos que no sólo pertenecen al pasado, sino que continúan sucediendo en la consecución del andar poético. Consignados en la emblemática figura de Jécar Negh$\mathrm{me}^{12}$, son igualmente disipados por los discursos oficiales de la aparente quietud («No

10 Dice el Canto XII de La Odisea (Homero) cuando Ulises se enfrenta a esas criaturas: «[...] la divina Caribdis ingiere las aguas oscuras. Las vomita tres veces al día, tres veces las sorbe con tremenda resaca y, si ésta te coge en el paso, ni el que bate la tierra podrá librarte de la muerte» (194). Entonces Ulises decide enfrentar a Escila y Circe le replica: «[... ] ella no es mortal, antes bien, una plaga sin muerte, un azote tremendo, agobiante, feroz e invencible» (194). Finalmente una gran cantidad de hombres sucumbe ante Escila. Como relata Ulises: «[...] me largaban los brazos aún en su horrible agonía: nunca tuve ante mis ojos tan triste visión entre todas cuantas he padecido en el mar [...]» (199).

11 Demás está decir que con estos versos la hablante también manifiesta su repugnancia sobre tal escenario: «mis cupidos», puede ser leído también como mis escupidos.

12 Estudiante de Historia del Pedagógico de la Universidad de Chile y dirigente mirista, asesinado un tiempo después del plebiscito, en septiembre de 1989. Otro de los casos emblemáticos de represión política pos- 
pasa nada», 39) y la abundancia económica («El barrio «turco» vive su última liquidación», 39). Los versos dedicados a él, y que recogen el rayado que en ese momento cubrió los muros de Santiago, se encuentran en el poema medular "Santiago Waria», titulado igual que el macrotexto, denotando su importancia. Esos versos que dicen «Viven los caras duras viven los cara'e palo/ ¡Jécar Vive!» (39), mantienen su poder denunciante hoy ante el insatisfactorio fallo judicial que cerró su caso ${ }^{13}$.

A ese atentado se unen las figuras fantasmales de las muertes acalladas que mantienen su presencia sobre la ciudad, «Lucho Durán» ${ }^{14}(38)$, «hombres y mujeres asediados» $(\mathrm{K})$, «alguna muñeca descabezada», «el revoltijo del patio 29»(N), imágenes centelleantes como «ritos de sangre gotean en la veredas/ hígados apuñalados/malares hundidos» (34). La hablante queda imantada por ellos y los sigue, "con una araña en el ojal», enlutada como una sombra tras el «hombre que dobló la esquina/ y duele su cuello guillotinado» (C), atenta a los lamentos que se oyen como «un ladrido humano en el estrépito» (T), voces desgarradoras de muertos y torturados que no han abandonado la ciudad y reclaman presencia en medio de la indolente masa humana, quebrando, desmontando con esos gritos el engañoso presente de la ciudad de «Estilo Callampero y Bursátil» $(\mathrm{X})$ condenada en su extravío ${ }^{15}$.

Con ese sentido de memoria, su ánimo colectivo va más allá, porque no se distingue sólo como espectadora y denunciante, sino también como víctima directa de esa violencia desmedida, la que, en su caso particular, manifiesta las señas del sometimiento sexogenérico. Protagonista de una escena que en nuestro país muchas mujeres omitieron por años y que sólo ahora comienza a conocerse (Jelin, "Militantes») ${ }^{16}$, expresa el sentido comunitario del padecimiento y apunta la diferenciación de la violencia en el sistema de género. Señala el poema titulado «Hueviche Súmmum»: "Cayó sobre mí una montaña ardiendo, una ruma de piedras caldeadas o me tragué un pan muy picante. Crucificada en los escalones yo sólo hubiera querido echar lava por la boca. Después estaba en cueros, sucia, goteando, como salida de un terremoto, pero intacta, y mi corazón parado de un solo campanazo» $(\mathrm{H})$.

En resistencia a las políticas del silenciamiento, el poema expone el propio cuerpo como lugar de memoria, tanto del trauma físico y emocional como de la innegable fisonomía de nuestra ascendencia indígena. En él la marca corporal vuelve a inscribir la

terior a esos comicios electorales corresponde a la tortura y asesinato de Cecilia Magni Camino y Raúl Pellegrin Friedman, aparecidos el 28 y 31 de octubre de ese año, respectivamente (Informe de la Comisión de Verdad y Reconciliación).

13 Conocido como el «último crimen de la dictadura», sus autores obtuvieron en marzo del 2009 la concesión del beneficio de «libertad vigilada» por bajas penas (Memoria Viva).

14 Luis Durán, estudiante de Periodismo de la Universidad de Chile y militante del MAPU, detenido el 4 de septiembre de 1974, presuntamente fuera de su casa, aunque no hay testigos de la detención, lo que parece recrear el sentido del texto poético: el lugar desapareció (Memoria Viva).

15 Dice Benjamin en la Tesis III: «El cronista, que detalla los acontecimientos sin discernir entre los grandes y pequeños, tiene en cuenta la verdad de que nada de lo que alguna vez aconteció puede darse por perdido para la historia. Por cierto, sólo a la humanidad redimida le concierne enteramente su pasado. Quiere decir esto: sólo a la humanidad redimida se le ha vuelto citable su pasado en cada uno de sus momentos» (49).

16 Señala Elizabeth Jelin al respecto: «Quizás sea esta ausencia de capacidad de escucha y su aparición mucho años después, para dar un ejemplo, lo que ha llevado a las mujeres chilenas a silenciar la violación sexual en la tortura, para quebrar todos esos silencios treinta años después, cuando se abrió un espacio institucional legítimo de escucha a través de la Comisión Nacional sobre Prisión Política y Tortura, con un informe hecho público en 2004». Y agrega: «En Argentina, el tema está saliendo del silencio sólo ahora» («Militantes», s.p.). 
filiación de la hablante con el lugar mapuche (recordemos el epígrafe inicial y el poema "Fuente Neptuno»), ya que aquí, al igual que Ngechén, ella es crucificada y, además, forzada sexualmente, aludiendo a la frecuente tortura que en dictadura buscaba indicar a las mujeres su lugar social al interior del sistema masculino. Pero, en este caso, el episodio además revive las múltiples violaciones que sufrieron las mujeres indígenas a manos de los españoles ${ }^{17}$, a partir de lo cual podemos concluir que para la voz central de $S W$ el lugar étnico y el genérico-sexual comparten igual situación subalterna.

En ese entramado la presencia de la cita de Pessoa, en la apertura textual («Mi conciencia de la ciudad es,/ por dentro, mi conciencia de mí»), resulta una guía crucial de lectura, porque su mención implica que el recorrido urbano tiene valor de reconocimiento y configuración personal, en palabras de Ricoeur, que «La memoria es erigida como criterio de identidad» (111). Y, más allá, que, en vista de las coordenadas que el texto va asentando, esa constitución es edificada en cuenta de su situación al interior del sistema sexo-género como experiencia singular, en vínculo a otras diferencias como son la política y la étnica. Ese trayecto identitario será reafirmado en los poemas finales (Y, Z), pero ya es expresado desde los inicios del texto, por ejemplo, en el poema «Ciudad interior», mediante una declaración transparente de sí misma, que sin pretensiones de figuración revela:

No puedo ser otra que la pensativa del Patio de los

Callados, la llorosa del Parque de los Reyes,

la olvidadiza

ni otra

que la que recoge papeles con sangre

Aquí podemos apreciar claramente que esa constitución de la identidad personal es realizada en contraste al despliegue de la manipulación concertada de la memoria y del olvido por parte de quienes sustentan el poder. Ello porque ambos lugares, cementerio y parque, son apuntados en su calidad de sitios marcados por ejecuciones e inhumaciones ilegales en el régimen militar, y luego intervenidos simbólicamente con monumentos recordatorios y zonas de áreas verdes por los gobiernos de la Concertación, sin un mayor trabajo de elaboración memorística ${ }^{18}$. La inauguración del Parque de los Reyes resulta un caso ejemplar en las "políticas de olvido» (Ricoeur, 111), ya que fue inaugurado paradójicamente en el Quinto Centenario del «descubrimiento de América», con la visita de los reyes de España incluida, generando amplios debates relativos a la «festividad» de lo que empezó a cuestionarse como el genocidio más grande de la historia universal: el de las etnias latinoamericanas. En ese gesto, igualado a la reestructuración del cerro Santa Lucía y la exposición internacional del iceberg, la hablante una vez más descubre las estrategias de ocultamiento de la brutal obtención del mando, la historia de la conformación de un país que, invisibilizando los cuerpos abusados, celebra su conquista y su progreso. En

17 Jorge Guzmán ha indicado la calidad de prisionera y el estatus socioeconómico desfavorecido de la hablante. Señala: «la hablante representada en este poema ocupa en la historia de Chile el lugar de los indios, de los pobres y es paciente de la misma violencia con que el invasor europeo afligió a la mujer mapuche» $(\mathrm{s} / \mathrm{p})$.

18 En ese sentido, Ricoeur alude a la relación que Freud establecía entre los síntomas histéricos, en cuanto síntomas mnemésicos, y los monumentos que adornan las ciudades. Entendiendo que los monumentos son respuestas a la pérdida, pero que más allá de ellos, el trabajo de duelo es coextensivo a toda la empresa psicoanalítica como renuncia y resignación que culmina en la reconciliación con la pérdida (100). 
medio de la aparente confusión de tal escenario, la hablante vaga afectada, reacomodando su memoria y haciéndose cargo del pasado, recogiéndolo desde el mismo suelo. Mas continúa transitando reflexiva, como Alicia en Las Ciudades (1974), la película de Wim Wenders, donde la pequeña Alicia, con grandes ojos, impactada, ve el paso de la ciudad ante su mirada ${ }^{19}$.

En ese sentido puede afirmarse que, al mismo tiempo que la falacia democrática cae en la exposición de sus dispositivos, la constitución de la propia identidad de la hablante se levanta reflectando su débil y burdo andamiaje, y así esa postura íntima, que refiere "Ciudad interior», se vuelve determinante y pública en la seña de su filiación política, cuando afirma: «Jota, no cambiaré ni una 〈jota〉 de lo escrito» (Jota se llama comúnmente en Chile a las Juventudes Comunistas), y que defiende a lo largo del texto en múltiples ocasiones, develando su falta de conformidad («no me explico tamaña ceremonia», Q) y su resistencia ("no he abandonado la componedura de huesos y cuerpo", U). De esa forma, el yo poético que en principio se develó otro respecto del personaje que llevaba el nombre real de la escritora, llega a una firme declaración de principios que inicia asumiendo su identidad de poeta a través de la ineludible inscripción de su seudónimo al interior del texto mismo, en un gesto que establece una continuidad entre la autora y el sujeto que ha experimentado las vivencias del Poema. Ese movimiento, que otorga un sentido de verdad a todo el discurso poético (Luján, 190), consigue dos propósitos en vínculo, fundamentales al proyecto poético: instalar la figura de la mujer en la escena literaria nacional y, a la vez, dar luz sobre toda una historia femenina que ha debido rearmarse a través de búsquedas y encuentros $\operatorname{propios}^{20}$. Su definición allí es completa: «Yo, Elvira Hernández, la del bardo estertor», la que en el poetizar deja la vida y que carece de contactos ilustres, que exige la reposición del pasado, la irritante voz para quienes hacen oídos sordos a los estruendos de la historia, la que se ha encontrado, la que se reconoce:

autora de sí misma

camina por la Coquille de San Sebastián

repitiendo a media lengua: aitor, aitor

como si dijera: «Padre, por qué me has abandonado»

Mientras ha determinado que «la ciudad ha caído» (K), levanta el proceso de su autoconstrucción, ampliando su crítica al usar la lengua vasca que fuera prohibida por la dictadura franquista para llamar al padre (aitor) y acusar la orfandad que carga desde el inicio del poema. Sin embargo, a pesar de esa constatación de quiebre, se asume habitante del margen («He envejecido en Los Aledaños», Z) y frente a ese llamado anónimo que la conmina al silencio y su condescendencia con la nueva sociedad modélica, después del largo viaje, que finalmente resulta ser el proceso de su propio encuentro, la hablante no puede, no podría responder, sino inquebrantable: «Mis armas son mi vida» $(\mathrm{Z})$.

19 Señala Félix, el protagonista: «Cada imagen irradia el mismo disgusto y nauseabundo mensaje. Ninguna imagen te deja tranquilo, todas desean algo de ti».

20 El mismo contexto cultural da razón a la postura poética, cuando en el año 1987, se realiza en Santiago el Congreso Internacional de Literatura femenina, calificado como «el evento literario más importante producido en Chile bajo dictadura». Respecto del cual Nelly Richards dice: «El Congreso articuló además el primer espacio colectivo donde las escritoras pudieron compartir una experiencia de lo literario vivenciada - y conceptualizada- desde la desigualdad material de su condición de género» («Presentación», 9). 
Así, podemos concluir que la ciudad que $S W$ describe es la representación de una sociedad, la nuestra, que ha construido su historia sobre una serie de exclusiones y silenciamientos de todo orden: genérico-sexual, en la violencia contra la mujer, político, en la persecución y olvido de los sectores contrarios a la ideología dominante aún hoy, y étnico, respecto de sus pueblos originarios. Lugar de una sucesión de tragedias, se presenta como imagen de cripta monumental, «la manifestación residual de la persistencia fantasmática de un duelo irresuelto» (Avelar, 20) ) $^{21}$ en un sentido homogéneo, pétreo, moribundo, reproduciendo su propio destino, Santiago, dice la voz poética:

\author{
parece mar \\ tierra embaldosada \\ hueso roído por hormigas \\ container funerario parece \\ una gran maternidad de basura (36).
}

Porque no ha hecho valer el precio de sus muertos, porque no se ha dictado justicia sobre ellos, porque, en su lugar, se ha vendido al mercado y ha instalado un dictum de olvido que intenta gobernar hasta las conciencias de sus ciudadanos ${ }^{22}$.

Finalmente, su hablante poética, detentando conscientemente los atributos de una diferencia proliferante, es capaz de denunciar los vicios que ha traído de vuelta la apreciada, pero inestable democracia. Mediante un proceso que, en lugar de plantear los desafíos de una reconstrucción evidente, que no podía ser sino compleja y conflictiva, disfrazó su desarrollo con un ambiente de pretendido orden y legalidad, sobre la base del letargo y el arreglo fraudulento. En la acusación de esas circunstancias, $S W$ deja en su trazo un testimonio indiscutido sobre la negligencia que, tanto a nivel de autoridades como de ciudadanos, nos ha imposibilitado la constitución de una comunidad sólida, capaz de enfrentar y enmendar sus faltas. Porque, tal como señala Moulian, mientras no sean admitidos, "Esos recuerdos bloqueados seguirán bajo la superficie realizando su daño sordo. Las heridas están localizadas en el inconsciente del Chile Actual» (37).

Así, en mi perspectiva, el valor poético y político que reviste $S W$, como elaboración de una memoria surgida desde la singularidad de la experiencia femenina, corresponde a ese acto de entrega absoluta al proceso de liberación del contenido traumático nacional, asumiendo el trabajo de duelo comunitario que no hemos sabido cómo enfrentar o imponer, y permitiéndonos una vía de sanación social. Es la autora y hablante poética quien acepta ese «secreto compromiso de encuentro» entre las generaciones del pasado y la nuestra, del cual nos hablara Benjamin (48), y también ella quien ha pagado el precio de su hazaña, de modo que, con la «cabeza vendada/ los ojos cerrados/ peregrina» (Y), finalizando su trayecto por la ciudad, ha sido oyente y relatora de nuestra memoria y, templando la mirada cansada, ha permitido desatar la opresión de ese universo de voces susurrantes

21 Allí, Avelar señala que para Abraham y Torok una teoría de la cripta sería inseparable de una teoría de lo espectral y de los fantasmas («Introducción»).

22 Los ejemplos a lo largo del texto son múltiples: «Tú te pones los zapatos del muerto/ compramos mercadería y flores» (34), «Jornada inolvidable/ olvidándote de ti» (35), "Tomamos un mariscal o un caldo de cabeza/ un traguito traslaticio» (37), "Lo otro se ha desvanecido, todo desaparece/ la vereda donde desapareció Lucho Durán» (38), «Por siglos seguiré hibernando» (39), «alejados de los alejados en el carrusel» (Ch), "es un lugar deshabitado como el olvido» $(\mathrm{T})$, los muchachos corren tras la pelota, los pechos descubiertos «como si no les entraran balas» (I), y el último verso de «NN» que dice: «y quizás eso no importe ene». 
que clamaban redención, exteriorizando la tumba interior que llevamos como sociedad, alumbrando una historia de alteridades oprimidas.

\section{REFERENCIAS}

Avelar, Idelber. Alegorías de la derrota: la ficción postdictatorial y el trabajo de duelo. Santiago: Cuarto Propio, 2000. Medio impreso.

Benjamin, Walter. Dialéctica en suspenso: fragmentos sobre historia. Santiago: Lom Ediciones, 2002. Medio impreso.

Freud, Sigmund. «La aflicción y la melancolía». Obras Completas. Madrid: Biblioteca Nueva, 1948. Medio impreso.

Guzmán, Jorge. «Otra Carta de Elvira Hernández». Elvira Hernández, Santiago Waria. Santiago: Cuarto Propio, 1996. Medio impreso.

Hernández, Elvira. Santiago Waria. Santiago, Chile: Cuarto Propio, 1996. Medio impreso.

Homero. La Odisea. Madrid: Gredos, 1982. Medio impreso.

Informe de la Comisión de Verdad y Reconciliación. Santiago: Andros, 1996. Medio impreso.

Jelin, Elizabeth. Los trabajos de la memoria. Madrid: Siglo XXI, 2002. Medio impreso.

_-_. "Militantes y combatientes en la historia de las memorias: Silencios, denuncias y reivindicaciones». Anuario Lucha Armada en la Argentina 5 (2010). 70-83. Medio impreso.

Luján, Ángel. «Figuras del enunciador lírico». Pragmática del discurso lírico. Madrid: Arco/libros, 2005. Medio impreso.

Memoria chilena. Sitio Web, 2011. Fecha de ingreso: 28 de julio de 2011.

Memoria Viva. Sitio web, 2011. Fecha de ingreso: 28 de julio de 2011.

Moulian, Tomás. Chile actual. Anatomía de un mito. Santiago, Chile: Lom Ediciones, 1997. Medio impreso.

Olea, Raquel. «Elvira Hernández. Autora de sí misma». Elvira Hernández, Santiago Waria. Santiago: Cuarto Propio, 1996. Medio impreso.

Oyarzún, Pablo. "Cuatro señas sobre experiencia, historia y facticidad. A manera de introducción». Walter Benjamin, Dialéctica en suspenso: fragmentos sobre historia. Santiago: Lom Ediciones, 2002. Medio impreso.

Richards, Nelly (ed.). Politicas y estéticas de la memoria. Santiago: Cuarto Propio, 2006. Medio impreso.

_. «Presentación». Escribir en los bordes. Santiago: Cuarto Propio, 1994. Medio impreso.

Ricoeur, Paul. La memoria, la historia, el olvido. Madrid: Trotta, 2003. Medio impreso. Rubin, Gayle. «El tráfico de las mujeres: notas sobre la «economía política del sexo». Nueva antropología VIII:30 (1986). 95 -145. Medio impreso.

Ruiz, Carlos. «Democracia, Consenso y Memoria: Una reflexión sobre la experiencia chilena». Politicas y Estéticas de la Memoria. Ed. Nelly Richard. Santiago: Cuarto Propio, 2006. Medio impreso. 
Violi, Patricia. El infinito singular. Madrid: Cátedra, 1991. Medio impreso.

Alicia en las ciudades. Wenders, Wim, dir. Act. Rüdiger Vogler, Yella Rottländer, Lisa Kreuzer. Produktion 1 im Filmverlag der Autoren / WDR, 1974. Medio fílmico.

Williams, Raymond. Marxismo y Literatura. Barcelona: Península, 1980. Medio impreso.

Recepción: 29 de julio de 2011 Aceptación: 17 de octubre de 2011 